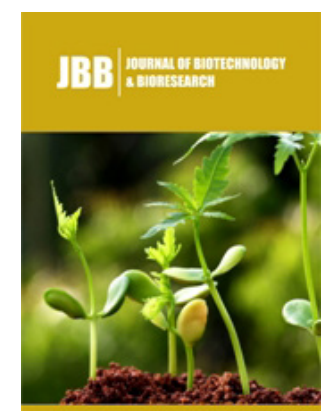

*Corresponding author: Hojouj Mohammad IM, Department of Oncology and Medical Radiology, Volodymyr Vernadskii str, 9, Dnipro, 49044, Ukraine

Submission: 侮July 02, 2019

Published: 酶July 12, 2019

Volume 2 - Issue 2

How to cite this article: Hojouj M IM, Igor Bondarenko, Viktor Z, Maltseva L, Elhaj M. A Rare Case of Sezary Syndrome Cutaneous T-Cell Lymphoma with Complete Response .J Biotech Biores.2(2). JBB.000531.2019.

Copyright@ Hojouj Mohammad IM, This article is distributed under the terms of the Creative Commons Attribution 4.0 International License, which permits unrestricted use and redistribution provided that the original author and source are credited.

\section{A Rare Case of Sezary Syndrome Cutaneous T-Cell Lymphoma with Complete Response}

\author{
Hojouj Mohammad IM${ }^{1 *}$, Igor. Bondarenko', Viktor Zavizion' ${ }^{1}$, Maltseva Liebov ${ }^{2}$, \\ Elhaj Mohamad ${ }^{1}$, Hurtovyi Vadym ${ }^{2}$, Hojouj Tamara ${ }^{1}$, Tereshchenko Pavlo ${ }^{1}$ and \\ Tereshchenko Sergii ${ }^{2}$ \\ ${ }^{1}$ Department of oncology and medical radiology, Ukraine \\ ${ }^{2}$ Municipal Institution Dnipropetrovsk City Multi-field Clinical Hospital, Ukraine
}

\begin{abstract} enlargement due to infiltration by similar cells. a variety of vague or unusual symptoms, including:

$\begin{array}{ll}\text { 1. } & \text { Peeled skin } \\ \text { 2. } & \text { Rash, which sometimes can itch } \\ \text { 3. } & \text { Mushroom-like skin lesions } \\ \text { 4. } & \text { Swollen lymph nodes, or painless lumps, in the skin } \\ \text { 5. } & \text { Unexplained fevers and weight loss }\end{array}$
\end{abstract}

Cutaneous T cell lymphoma is one of non-Hodgkin's lymphoma. Several types of cutaneous T-cell lymphoma exist. The most common type is mycosis fungoides. Sezary syndrome is a less common type that causes skin redness over the entire body. The common symptoms of Sezary syndrome are erythroderma, leukemia with circulating mononuclear cells having convoluted nuclei and lymph node

Lymphoma starts in the lymphocytes, or the cells in the immune system that are normally found in the lymphatic system. If lymphocytes start growing out of control, they can build up and form a cancerous collection of cells in the skin that can lead to lymphoma. Patients with skin lymphoma might experience

Skin lymphoma usually is well behaved and doesn't spread throughout the body. However, it has the potential to do so in approximately 15 to 20 percent of cases. At the specialized skin lymphoma clinic at UT Southwestern, we offer a range of treatment options to effectively beat the two specific types of skin lymphoma and their various subtypes [1-4].

Sezary syndrome is an aggressive form of cutaneous T-cell lymphoma which is a group of disorders that occur when T-cells (a type of white blood cell) become cancerous and affect the skin. It is characterized by a widespread red rash that may cover most of the body, the presence of cancerous $\mathrm{T}$ cells (called Sezary cells) in the blood, and abnormally enlarged lymph nodes. Other signs and symptoms may include intense itchiness, scaling and peeling of the skin; fever; weight loss; hair loss; outward turning of the eyelids (ectropion); palmoplantar keratoderma; malformation of the nails; and hepatosplenomegaly. The exact cause of Sezary syndrome is currently unknown. Treatment varies based on the signs and symptoms present in each person and the severity of the condition.

Prognosis: The long-term outlook (prognosis) for people with Sezary syndrome is generally poor. Sezary syndrome is difficult to cure. Treatment is usually palliative, with the intention of relief of symptoms and improvement in the quality of life. Median survival for patients with Sezary syndrome has been reported to be 2 to 4 years after development of the condition, although survival has improved with newer treatments. The disease-specific 5-year survival rate has been reported to be $24 \%$. We present 1 case of Sezary syndrome which happened in our hospital with complete response.

Keywords: Cutaneous T-cell lymphoma; Rare cancers; Pruritus; Sezary syndrome; Chemotherapy

\section{Case Report}

A 47-year-old female was admitted to the hospital with general weakness, sweating and the existence of the painless formation in the left inguinal region. The rise of temperature up to $37.5{ }^{\circ} \mathrm{C}$ Rash-like skin redness, slightly raised or scaly round patches on the skin. Abnormalities of the fingernails and toenails [5-7]. 


\section{Status locales}

Third stage is characterized by the formation of the purple-red tumor with a bluish tinge $85 \%$.

\section{Anamnesis vitae}

HAV antigen, Hepatitis B antigen, HCVab are negative. Sexually transmitted diseases, HIV are negative. Blood transfusion wasn't performed during the life. The patient denied any allergically reactions to any medicament ions.

\section{Objective status}

The general condition of patient is satisfactory. ECOG -0 point. The patient has regular build. The skin and visual mucous coat have normal healthy color. Glandules mammaria are soft without any pathological features. The chest is symmetrical, normal form. There is vesicular resonance without any pathological pulmonary rales during the auscultation. On the side of heart, soft heart sounds are auscultated. Abdomen is symmetrical, painless during the palpation. The liver is palpated at the edge of the costal arch. The edge is soft, elastic. The spleen is not palpable. The area of kidneys without any pathological features. Symptom of Pasternack is negative from 2 sides. Physiological functions are not impaired. The symptoms of neuropathy are negative. There is no evidence of metastatic affection of CNS. There are no findings about symptomatic or progressive meningeal infiltration. Any additional symptoms of NHL are not identified [8,9].

\section{Status Locales}

Conglomerations of increased lymph nodes are palpated from two sides. The size of the right conglomeration is $8 \times 7 \mathrm{sm}$., and the size of the left conglomeration is $6 \times 7 \mathrm{sm}$. The postoperative cicatrix is soft and healthy in the supraclavicular region. The other lymph nodes are not palpated.
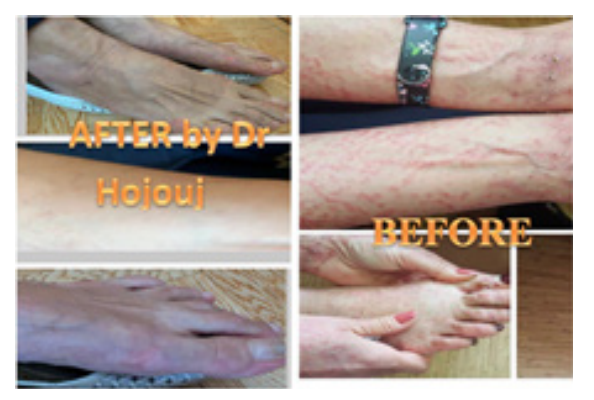

Figure 1:
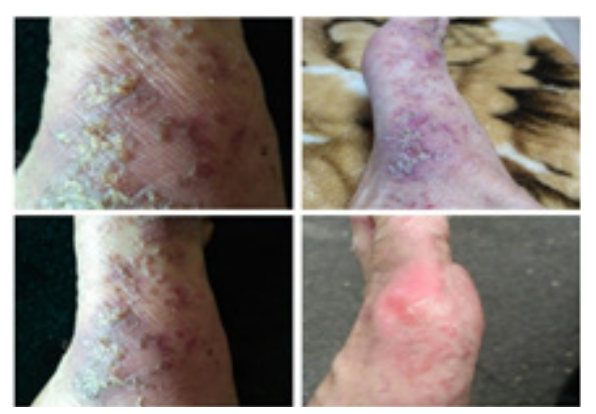

Figure 2:
Based on complaints, history of the disease, these additional methods examinations, the patient has a clinical diagnosis: Cutaneous Lymphoma T3N0M0 st. IIB, clinical group 2 Figure $1 \& 2$.

After the clinical diagnosis was made, the patient was prescribed to do followings analyses:

1. Clinical blood test

2. Simple urine test

3. Biochemical blood assay

4. Total protein

5. Coagulogram

6. MNS blood group

7. AXR

8. Abdominal ultrasound

9. WBBS

\section{Investigations}

Table 1 \& 2 MNS blood group-blood group (09.10. 2018): (A), Rh $(+)$. MSCT of thoracic region, abdominal region, cavity organs and pelvic organs (03.08.2018): the character of lymphoproliferative disorder. Pelvic examination: without pathological findings.

Table 1: CBC

\begin{tabular}{|c|c|}
\hline HBG & $115 \mathrm{~g} / \mathrm{l}$ \\
\hline RBC & $4,14 * 109$ \\
\hline WBC & $10 * 9$ \\
\hline ESR & $6 \mathrm{~mm}$ per hour \\
\hline
\end{tabular}

Table 2: Biochemistry of blood.

\begin{tabular}{|c|c|}
\hline BLD & $73 \mathrm{mkmol} / \mathrm{l}$ \\
\hline GOT & 16 \\
\hline ALT & 13 \\
\hline SUN & 3.0 \\
\hline Creatini serum & 76 \\
\hline
\end{tabular}

\section{Pharmacological therapy}

Among the treatment, Kenalog and bandage was prescribed by the doctor. Elective operation was performed in January 14, 2018. It was consisted of excisional left inguinal lymph node biopsy. The wound healed by primary intention healing. After the operation 6 combination chemotherapy treatment cycles was set up by the doctor. The patient was routinely admitted in order to give the 1 course of treatment [10-12]. It was also recommended to register with the oncologist at the place of residence.

\section{Patient diary}

June 13, 2018 Performance status is satisfactory. Patient has complaints of pain in the left breast. Abdomen is symmetrical, painless during the palpation. Bowel movements and diuresis are within normal. ABPM 120/80, heart rate 70 per minute $[13,14]$. 
The patient takes following medicine:

1. Cyclophosphamide $1000 \mathrm{mg} 1$ day

2. Methotrexate $1000 \mathrm{mg} 1$ day

3. Leucovorin $1200 \mathrm{mg}$ intravenous 1 day

4. Oxaliplatin $200 \mathrm{mg} 1$ day

5. Gemcitabine $2000 \mathrm{mg} 2$ day

The performance status of patient during the treatment was satisfactory during the treatment. After the examination the patient was prescribed ambulant therapy Figure 3.

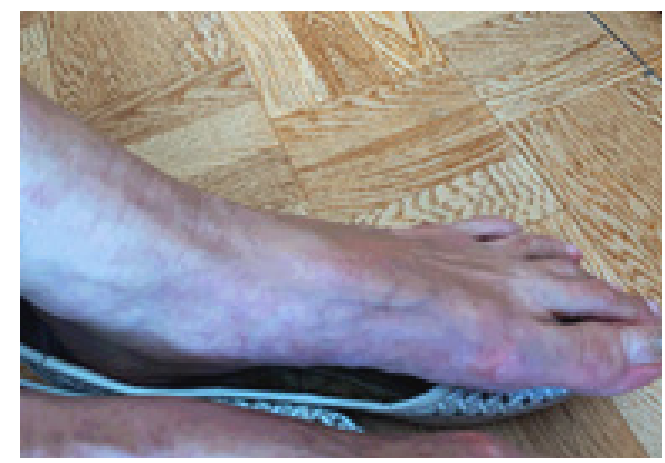

Figure 3:

\section{Statement of ethics}

The patient gave written informed consent.

Figure 4 Histologic appearance of the skin lesion. Bandlike small-lymphocyte infiltrates with several epidermotropic lymphocytes were observed. On high power magnification Infiltrates consist of histiocytes, lymphocytes and atypical cells with medium-sized, highly indented (so-called cerebriform) nuclei. Typical Paltrier micro abscesses were not observed in the lesions.

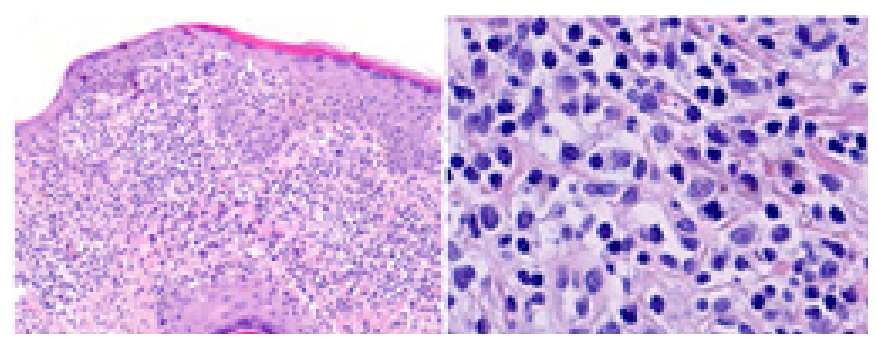

Figure 4: Biopsy of the skin lesion (patch/thin plaque) was performed from the elbow region.

\section{Conclusion}

We believe that this presentation of SC is underreported, and many patients are likely misdiagnosed as having high-grade cutaneous T-cell lymphomas and inappropriately treated with nonHodgkin's lymphoma-(NHL-) type regimens. Delay in diagnosis and inappropriate treatment will adversely affect the outcome of this aggressive disease. With this case report and literature review, we therefore would like to increase awareness of cutaneous only presentation of TLBL. extremely rare and unique form of cutaneous lymphoma that can have potentially fatal consequences if undiagnosed; therefore, clinicians must take great care to make the correct diagnosis based on a knowledge of the clinical and immunohistochemical findings.

\section{References}

1. Willemze R (2008) Cutaneous T-cell lymphoma. In: Bolognia JL, et al. Dermatology. (second edition). Mosby Elsevier, Spain, 1867-1886.

2. Bagherani $\mathrm{N}$ and Smoller BR (2016) An overview of cutaneous $\mathrm{T}$ cell lymphomas. F1000Res.

3. Horwitz SM, Ansell SM, Ai WZ, Barnes J, Barta SK, et al. (2018) National Comprehensive cancer network: Clinical practice guidelines in oncology: T-cell lymphomas. Version 3.2018.

4. Hosing C, Bassett R, Dabaja B, Talpur R, Alousi A, et al. (2015) Allogeneic stem-cell transplantation in patients with cutaneous lymphoma: updated results from a single institution. Ann Oncol 26(12): 2490-2495.

5. Jawed SI, Myskowski PL, Horwitz S, Moskowitz A, Querfeld C (2014) Primary cutaneous T-cell lymphoma (mycosis fungoides and Sezary syndrome) Part I. Diagnosis: Clinical and histopathologic features and new molecular and biologic markers. J Am Acad Dermatol 70(2): 205. e1-16.

6. Lauren CPB MD (2015) Cutaneous T-cell lymphoma. Medscape Reference.

7. Mycosis Fungoides and the Sézary Syndrome Treatment (PDQ®). National Cancer Institute.

8. Elise A Olsen MD, Alain H Rook MD (2013) Clinical presentation, pathologic features, and diagnosis of Sézary syndrome. UpToDate.

9. Sézary syndrome (2013) Genetics home reference.

10. Clark RA (2010) Skin resident T cells: The ups and downs of onsite immunity. J Invest Dermatol 130(2): 362-370.

11. Habif TP, Campbell JL (2006) Cutaneous T-cell lymphoma. In: Dermatology DDxDeck. Mosby Elsevier, China.

12. Jawed SI, Myskowski PL, Horwitz S, Moskowitz A, Querfeld C (2014) Primary cutaneous T-cell lymphoma (mycosis fungoides and Sezary syndrome): Part I. Diagnosis: Clinical and histopathologic features and new molecular and biologic markers. J Am Acad Dermatol 70(2): 205. e1-16.

13. Sahni D (2018) What's new in cutaneous T-cell lymphoma. In: Novel therapies for cutaneous malignancies: What's new and what's ahead." 2018 Annual Meeting of the American Academy of Dermatology.

14.Wilcox RA (2017) Cutaneous T-cell lymphoma: 2017 update on diagnosis, risk-stratification, and management. Am J Hematol 92(10): 1085-1102. 